\title{
Patient-reported symptom distress, and most bothersome issues, before and during cancer treatment
}

\author{
Fangxin Hong ${ }^{1,2}$ \\ Traci M Blonquist' \\ Barbara Halpenny ${ }^{3}$ \\ Donna L Berry ${ }^{3,4}$ \\ 'Department of Biostatistics and \\ Computational Biology, Dana-Farber \\ Cancer Institute, Boston, MA, \\ USA; ${ }^{2}$ Department of Biostatistics, \\ Harvard School of Public Health, \\ Boston, MA, USA; ${ }^{3}$ Department of \\ Nursing and Patient Care Services, \\ The Phyllis F. Cantor Center, \\ Dana-Farber Cancer Institute, \\ Boston, MA, USA; ${ }^{4}$ Department of \\ Medicine, Harvard Medical School, \\ Boston, MA, USA
}

This article was published in the following Dove Press journal:

Patient Related Outcome Measures

12 September 2016

Number of times this article has been viewed

Introduction: Frequently reported symptoms and treatment side effects may not be the most bothersome issues to patients with cancer. The purpose of this study was to investigate patientreported symptom distress and bothersome issues among participants with cancer.

Methods: Participants completed the Symptom Distress Scale-15 before treatment (T1) and during cancer treatment (T2) and reported up to two most bothersome issues among symptoms rated with moderate-to-severe distress. We compared symptom ratings and perceived bother and explored two approaches predicting patients' most bothersome issues: worst absolute symptom score or worst change from pretreatment.

Results: Significantly, $(P \leq 0.0002)$ more patients reported moderate-to-severe distress at T2 for eight of 13 symptoms. At T1, 81\% of patients reported one and $56 \%$ reported multiple symptoms with moderate-to-severe distress, while at T2, 89\% reported one and $69 \%$ reported multiple symptoms with moderate-to-severe distress. Impact on sexual activity/interest, pain, fatigue, and insomnia were the most prevalent symptoms with moderate-to-severe distress. Fatigue, pain, and insomnia were perceived most often as bothersome. When one symptom was rated moderate-to-severe, predictive accuracy of the absolute score was $46 \%$ and $48 \%$ (T1 \& T2) and 38\% with the change score (T2-T1). When two or more symptoms were rated moderate-to-severe, predictive accuracy of the absolute score was 76\% and 79\% (T1 \& T2) and $70 \%$ with the change score (T2-T1).

Conclusion: More patients experienced moderate-to-severe symptom distress after treatment initiation. Patient identification of bothersome issues could not be assumed based on prevalence of symptoms reported with moderate-to-severe distress. The absolute symptom distress scores identified patients' most bothersome issues with good accuracy, outperforming change scores. Keywords: symptom distress, perceived bother, SDS-15, prediction, most bothersome issues

\section{Introduction}

Patients with cancer often experience distress associated with disease-related symptoms or treatment-related side effects. The phrase "symptom distress" was originally defined in McCorkle and Young's ${ }^{1}$ definition applied in development of the Symptom Distress Scale (SDS), "the degree of discomfort from the specific symptom(s) being experienced (and) as reported by the patient" (p. 374). We refer to distress as the intensity and frequency of a symptom that is experienced and reported by the patient, measured by the SDS. Investigators have documented the negative relationships between symptom distress and adults' quality of life (QOL) both physically and psychologically before and during active medical cancer therapy, ${ }^{2,3}$ postoperatively, ${ }^{4}$
Correspondence: Fangxin Hong Department of Biostatistics and Computational Biology, Dana-Farber Cancer Institute, Harvard School of Public Health, 450 Brookline Avenue, mailstop CLSB I I007, Boston, MA 02115, USA

Tel +I 6176323602

Fax +I 6176322444

Email fxhong@jimmy.harvard.edu 
as well as during survivorship. ${ }^{5}$ Monitoring patient-reported cancer-related symptoms and quality of life (SxQOL) is becoming standard practice in cancer care and clinical trials. Clinical studies have shown that monitoring SxQOL with patient-reported outcomes can be efficient ${ }^{6}$ and was associated with improved clinician-patient communication and outcomes. ${ }^{7}$ Self-report tools can help clinical staff assess and make informed decisions about symptom management. Clinical investigators have used SxQOL measures to monitor and compare various regimens and also to test the efficacy of interventions intended to reduce symptoms distress and improve QOL. ${ }^{8}$ There are various symptom measurement tools that can provide numerical ratings of symptom distress (intensity and frequency)., ${ }^{9,10}$

On the other hand, symptom bother is a different concept that measures the perceived importance of a symptom when it worries, disturbs, or upsets patients. Yet, few studies help us understand the relative bother level experienced by patients who report the intensity, frequency, or distress of a particular symptom. The most intense or frequent SxQOL issues may not be the highest priority for patients due to a differential in perceived importance or bother; conversely, less intense or frequent symptoms may be perceived as bothersome. In a study of prostate cancer survivors, Brassell et $\mathrm{al}^{11}$ reported symptom bother scores changing over 24 months in the same direction as the symptom status domains but that bother varied in magnitude between adverse symptom outcomes. Hoekstra et $\mathrm{al}^{12}$ analyzed self-reported cancer symptom presence, severity, and troublesomeness (bother) in 152 Dutch inpatients with advanced cancer, and reported that assessing bother revealed a third of the sample for whom the most "troublesome" symptom was not ranked as the most severe. Assessing relative bother is of practical importance. Knowledge of symptom intensity, frequency, and bother reported by patients before and during treatment would help health providers identify and address patients' issues, integrate the information with objective clinical data, and provide required therapy modifications, supportive care, and/ or self-care education. A clinician might ask, "Why don't we just ask our patients what is bothering them the most?" Unfortunately, communication barriers exist, and there is evidence that clinicians interrupt patients during symptom reports ${ }^{13}$ and use close-ended questions more often than openended ones, precluding a full description of the symptom. ${ }^{14,15}$ Furthermore, patients may want to be the good and strong patient, reluctant to verbalize problems. ${ }^{16}$

Snyder et $\mathrm{al}^{17}$ demonstrated that the European Organization for Research and Treatment of Cancer Core Quality of
Life Questionnaire (QLQ-C30) was useful in identifying patients' most bothersome issues. The C30 domain scores were analyzed with two approaches to understand the best prediction of bother: 1) the worst subscale scores in absolute terms and 2) the greatest worsening change from the previous assessment point. With a sample of 130 patients receiving outpatient palliative chemotherapy for various cancers in the Netherlands, the authors concluded that absolute scores on a given day identified patients' bothersome issues better than change scores. However, the results have not been verified in other studies with a US patient population or with other SxQOL questionnaires. Furthermore, it is not clear whether the findings apply to SxQOL issues collected longitudinally from pretreatment and throughout active treatment.

The purpose of this analysis was to explore cancer symptom distress levels before and after treatment initiation, patient-reported bother among intense and/or frequent symptoms, and whether self-reported SDS symptom scores would predict the symptoms that patient identified as most bothersome.

\section{Methods}

This study was a secondary analysis of data from a randomized controlled trial of the Electronic Self-Report Assessment for Cancer conducted in two comprehensive cancer centers from April 2009 to June 2011 with approval by the institutional review boards of the Fred Hutchinson Cancer Research Center/University of Washington Cancer Consortium and the Dana-Farber Cancer Institute. ${ }^{7}$ Participants provided written informed consent to participate in the study. The details of the trial have been reported elsewhere. ${ }^{7}$ In brief, a total of 775 adult, ambulatory patients with any type or stage of cancer, and about to start a new anticancer therapy, were randomized to receive usual education about SxQOL topics or usual education plus the opportunity to self-monitor when not in the clinic, tailored self-care instruction for SxQOL issues, and communication coaching on how to report each SxQOL to clinicians. In the primary analysis, we detected a significant difference between study groups in mean SDS-15 score change from baseline to end of study. SDS-15 score was reduced by an estimated 1.21 (95\% confidence interval, $0.23-2.20 ; P=0.02)$ in the intervention group. Baseline SDS15 score $(P<0.001)$ and clinical service $(P=0.01)$ were found predictive for SDS-15 score change.

The Electronic Self-Report Assessment for Cancer screened for cancer-related SxQOL issues before treatment (T1) and at specific time points throughout the patient's therapy for both groups. A 15-item version of the SDS (SDS-15), ${ }^{7}$ 
which assesses distress within the past week (including today), was included and covered the following symptoms: physical appearance concerns, appetite issues, bowel issues, breathing issues, concentration, cough, fatigue, outlook (fear/worry), fever/chills, nausea (two items), pain (two items), impact on sexual activity/interest, and insomnia. Each SDS-15 item had a five-point response option list ranging from 1 (no or minimal distress) to 5 (maximal distress); each response option was characterized by phrases describing increasing levels of symptom frequency and/or intensity. Symptom items with responses of $\geq 3$ were considered moderate-to-severe and were displayed to the patient in an on-screen list after completing the assessment. Each participant was asked to choose (up to) two most bothersome SxQOL issues from the list. We selected two time points for this analysis: pretreatment (T1) and approximately 5 weeks after treatment initiation (T2).

\section{Analytic procedure}

The percentages of participants who reported a given symptom at moderate-to-severe distress were calculated and compared between $\mathrm{T} 1$ and $\mathrm{T} 2$ using McNemar tests. The percentages selecting a given symptom as most bothersome were also computed. Using Fisher's exact tests, we explored the impact of age ( $<50$ vs $\geq 50$ years) and sex on sexual activity/interest because of general perceptions that age and sex may influence this variable. The frequencies of the actual item responses $(3,4$, or 5) were explored for symptoms deemed moderate-to-severe. The frequencies with which a symptom was selected as a most bothersome issue were then computed for each response.

Two approaches were used to evaluate whether SDS-15 scores could accurately identify the issues participants reported as most bothersome. The first approach used absolute SDS-15 item scores with the highest score(s) indicating the worst symptom(s) experienced. Two SDS-15 items assessing frequency and intensity for pain and nausea were collapsed into one category each, and the higher of the two responses was used. We selected the two symptoms with the highest scores to predict the participant's two most bothersome issues. All participants who reported at least one symptom with moderate-to-severe distress were included regardless of whether a participant selected any or none as a bothersome issue. The predictions were conducted for T1 and T2 separately.

For the second approach, the SDS-15 change score was obtained by subtracting the item scores at T1 from the corresponding scores at T2. Similarly, among frequency and intensity for pain or nausea, the item with a larger positive difference was used to represent that symptom. The top two symptoms with the largest positive difference, indicating worsening symptomatology, were selected to predict the participant's most bothersome issues at T2. Only participants who had at least one worsening symptom were included.

Figure 1 illustrates how the prediction of the top two most bothersome issues was made from SDS-15 scores. Symptoms with the same score were given the same rank. When ties were present, all tied symptoms were included in the prediction. For example, for a given participant, within symptoms rated moderate-to-severe, if one symptom had a rank of 1 and one or more symptoms with a rank of 2 , then both rank 1 and 2 symptoms were included; if one or more symptoms had a rank of 1 , then only symptoms with rank of 1 were used. Essentially, we had two or more predictions for the most bothersome issues if two or more symptoms rated with moderate-to-severe distress, and one prediction if only one symptom was reported with moderate-to-severe distress.

Accuracy was quantified as the percentage of participants in whom the most distressing symptoms, based on the absolute score or change score, correctly identified one or both of the participant's most bothersome issues. Since the approach with change score included only participants with at least one worsening symptom, only the T2 time point was considered when comparing the two approaches. A sensitivity analysis for the comparison was performed using the sample in the change score approach. In addition, whether or not the change score added additional information for the prediction to the absolute score was explored. Specifically, the two most distressing symptoms based on the change score and the absolute score were combined for prediction at T2.

\section{Results}

The randomized controlled trial sample has been described previously. ${ }^{7}$ For this analysis, 2 and 74 participants, at T1 and T2, respectively, did not answer any SDS-15 item and thus were excluded. In addition, 88 and 84 participants, at $\mathrm{T} 1$ and T2, respectively, did not advance to view the page for selecting the most bothersome issues, and also were excluded from the analysis. The final analytical dataset included 662 participants at T1 and 594 participants at T2. Sample characteristics for this analysis are listed in Table 1.

The prevalence of symptoms with moderate-to-severe distress (a score of $\geq 3$ ) ranged from $2 \%$ (fever/chills) to $45 \%$ (impact on sexual activity/interest) before treatment, and 3\% (fever/chills, breathing) to 53\% (impact on sexual activity/ interest) during treatment. Approximately $81 \%, 56 \%$, and $40 \%$ of participants at $\mathrm{T} 1$, and $89 \%, 69 \%$, and $51 \%$ of participants at $\mathrm{T} 2$, reported at least 1,2 , or 3 symptoms, respectively, with moderate-to-severe distress. On average, participants reported 2.9 (standard deviation $[\mathrm{SD}]=2.0)$ at $\mathrm{T} 1$ and $3.4(\mathrm{SD}=2.1)$ symptoms with moderate-to-severe distress at $\mathrm{T} 2$. 
Thirteen symptoms

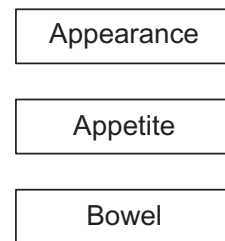

Breathing

Concentration
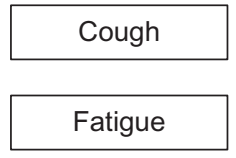

Fear/worry

Fever/chills

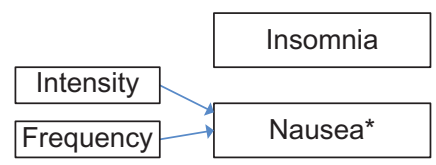

Intensity Pain* $^{*}$

Sexual activity/

interest
Prediction of top most

bothersome issues

1 symptom with moderateto-severe distress

Highest symptom

score

( 1 symptom)

$\geq 2$ symptoms with moderateto-severe distress

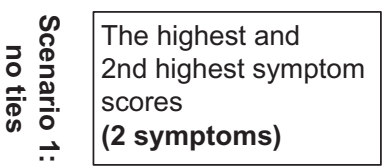

distress item scores $^{* *}$

\section{Descending} order

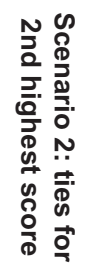

The highest and tied 2nd highest symptom scores ( $\geq 3$ symptoms)

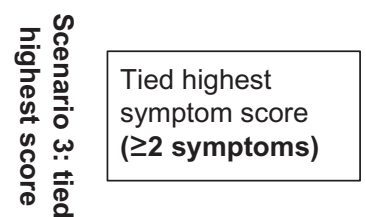

Test the prediction of top 1-2 most bothersome issues

Figure I Schema of prediction of top one to two most bothersome issues from the patient self-reported symptom score measured by SDS.

Notes: *Take the higher absolute score (Approach I) or larger positive difference (Approach 2) of "intensity" and "frequency". **Based on the absolute score (Approach I) or the change score (Approach 2); only include symptoms reported with moderate-to-severe distress.

Abbreviation: SDS, Symptom Distress Scale.

Table I Baseline patient characteristics for sample included in the analysis before (TI) and during (T2) treatment

\begin{tabular}{lll}
\hline Patient characteristic & Time I, N (\%) & Time 2, N (\%) \\
\hline $\begin{array}{l}\text { Number of patients } \\
\text { Age, median (range) }\end{array}$ & 662 & 594 \\
$\begin{array}{l}\text { Study group } \\
\quad \text { Control }\end{array}$ & $57.5(21.6-87.8)$ & $57.0(21.6-87.8)$ \\
$\quad$ Intervention & $347(52)$ & $317(53)$ \\
Sex & $315(48)$ & $277(47)$ \\
$\quad$ Male & $347(52)$ & $306(52)$ \\
Female & $315(48)$ & $288(48)$ \\
Education & & \\
$>$ High school & $523(79)$ & $466(78)$ \\
$\leq$ High school & $138(21)$ & $127(21)$ \\
$\quad$ Unknown & $1(<1)$ & $1(<1)$ \\
Work status & & $189(32)$ \\
Not working & $218(33)$ & $349(59)$ \\
Working & $382(58)$ & $56(9)$ \\
Unknown & $62(9)$ & $484(81)$ \\
Minority status & & $55(9)$ \\
No & $536(8 I)$ & $55(9)$ \\
Yes & $60(9)$ & \\
Unknown & $66(10)$ & \\
\hline
\end{tabular}

At least $25 \%$ of participants reported moderate-to-severe distress levels for impact of cancer and/or treatment on sexual activity/interest, pain, fear/worry, fatigue, and insomnia at T1 (Figure 2). Approximately 5 weeks after the start of cancer therapy (T2), at least $25 \%$ of participants reported moderateto-severe distress nearly the same as at T1, with the addition of appetite loss and the deletion of fear/worry. Overall, significantly $(P \leq 0.0002)$ more participants reported moderateto-severe distress after receiving treatment for eight of the 13 symptoms (Figure 2). Approximately $15 \%$ more participants reported fatigue and appetite loss, whereas approximately $10 \%$ more participants reported nausea and bowel problems at $\mathrm{T} 2$ compared with $\mathrm{T} 1$. The only symptom reported significantly less often at T2 was fear/worry $(P<0.0001)$.

The symptoms participants reported most commonly as "bothersome" both before and during treatment were fatigue, pain, and insomnia (Figure 2). Once reported on the SDS-15 with moderate-to-severe distress, cough, fatigue, fear/worry, and insomnia were the four symptoms perceived as the most 


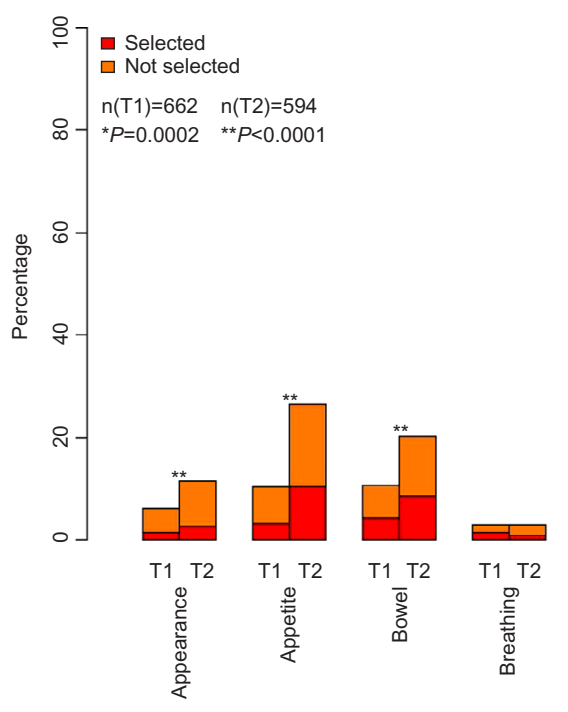

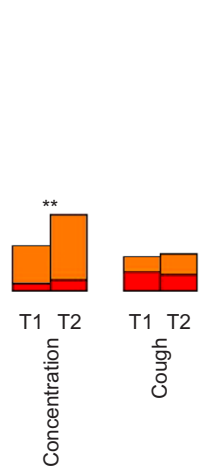

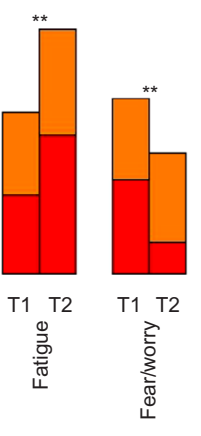

Symptom

Figure 2 For each symptom, percentage of patients (the whole bar) reporting a moderate-to-severe distress (3, 4, and 5 on 5-point response) and percentage of patients selecting (red) and not selecting (orange) the symptom as a most bothersome issue, before ( $\mathrm{TI}$ ) and during ( $\mathrm{T} 2$ ) a new cancer treatment.

Table 2 For impact on sexual activity/interest, the frequencies and percentage reported at moderate-to-severe distress, and the frequencies and percentage selected as most bothersome among all patients and among patients who reported moderate-to-severe distress, before (TI) and during treatment (T2)

\begin{tabular}{|c|c|c|c|c|c|c|}
\hline \multirow{2}{*}{$\begin{array}{l}\text { Patient } \\
\text { characteristics }\end{array}$} & \multicolumn{3}{|l|}{ TI } & \multicolumn{3}{|l|}{ T2 } \\
\hline & $\begin{array}{l}\text { Number of } \\
\text { patients }\end{array}$ & $\begin{array}{l}\text { Number (\%) } \\
\text { moderate-to-severe } \\
\text { sexual impact }\end{array}$ & $\begin{array}{l}\text { Number }\left(\%^{\mathrm{a}}, \%^{\mathrm{b}}\right) \\
\text { selected as most } \\
\text { bothersome }\end{array}$ & $\begin{array}{l}\text { Number of } \\
\text { patients }\end{array}$ & $\begin{array}{l}\text { Number (\%) } \\
\text { moderate-to-severe } \\
\text { sexual impact }\end{array}$ & $\begin{array}{l}\text { Number }\left(\%^{\mathrm{a}}, \%^{\mathrm{b}}\right) \\
\text { selected as most } \\
\text { bothersome }\end{array}$ \\
\hline \multicolumn{7}{|l|}{$\overline{\text { Age }}$} \\
\hline$<50$ years & 192 & 78 (4l\%) & I7 (9\%, 22\%) & 174 & $80(46 \%)$ & $13(7 \%, 16 \%)$ \\
\hline$\geq 50$ years & 470 & $219(47 \%)$ & 59 (13\%, 27\%) & 420 & $236(56 \%)$ & $43(10 \%, 18 \%)$ \\
\hline \multicolumn{7}{|l|}{ Sex } \\
\hline Male & 347 & I76 (5I\%) & $60(17 \%, 34 \%)$ & 306 & 193 (63\%) & 42 (14\%, 22\%) \\
\hline Female & 315 & 121 (38\%) & $16(5 \%, 13 \%)$ & 288 & $123(43 \%)$ & 14 (5\%, | | \%) \\
\hline
\end{tabular}

Notes: aPercentage of all patients; 'Percentage among patients with moderate-to-severe distress.

bothersome issues before treatment by approximately half the participants (Figure 2). The pattern remained the same at $\mathrm{T} 2$, except for fear/worry, which only $26 \%$ of the participants who reported it at moderate-to-severe perceived it as a most bothersome issue. The impact of cancer and/or treatment on sexual activity/interest was the most frequently reported symptom with moderate-to-severe distress both before (45\%) and during (53\%) treatment, but only $26 \%$ (T1) and $18 \%$ (T2) participants regarded it as a most bothersome issue. Bother associated with nausea at moderate-to-severe distress increased from $18 \%$ pretreatment to $42 \%$ during therapy.

For the impact on sexual activity/interest, sex was significantly associated with the prevalence of moderate-to-severe distress with higher prevalence in men both before treatment $(P=0.002)$ and during treatment $(P<0.0001)$. Participants aged $\geq 50$ years were found to have higher prevalence ( $P=0.02)$ during treatment. Once rated moderate-to-severe, the selection of impact on sexual activities/interest as a most bothersome issue was significantly higher in men compared with women both before $(P<0.0001)$ and during $(P=0.02)$ treatment (Table 2).

Among symptoms reported with moderate-to-severe distress, the majority ( $>50 \%)$ were moderate (scored a 3 on the SDS-15), whereas fear/worry, pain, impact on sexual activity/ interest, and insomnia were scored more severe ( 4 or 5 ). These levels of distress patterns were the same both before and during treatment. When examining the actual item responses for those symptoms selected as most bothersome, there was no clear pattern that a higher score (eg, 5 vs 3 or 4 ) led to a higher probability of selection as a bothersome issue (Figure 3).

Using SDS-15 item scores to identify participants' most bothersome issues, 533 participants at $\mathrm{T} 1$ and 527 participants at $\mathrm{T} 2$ reported at least one symptom with moderate-to-severe distress. If a participant reported only one symptom with mod- 
A

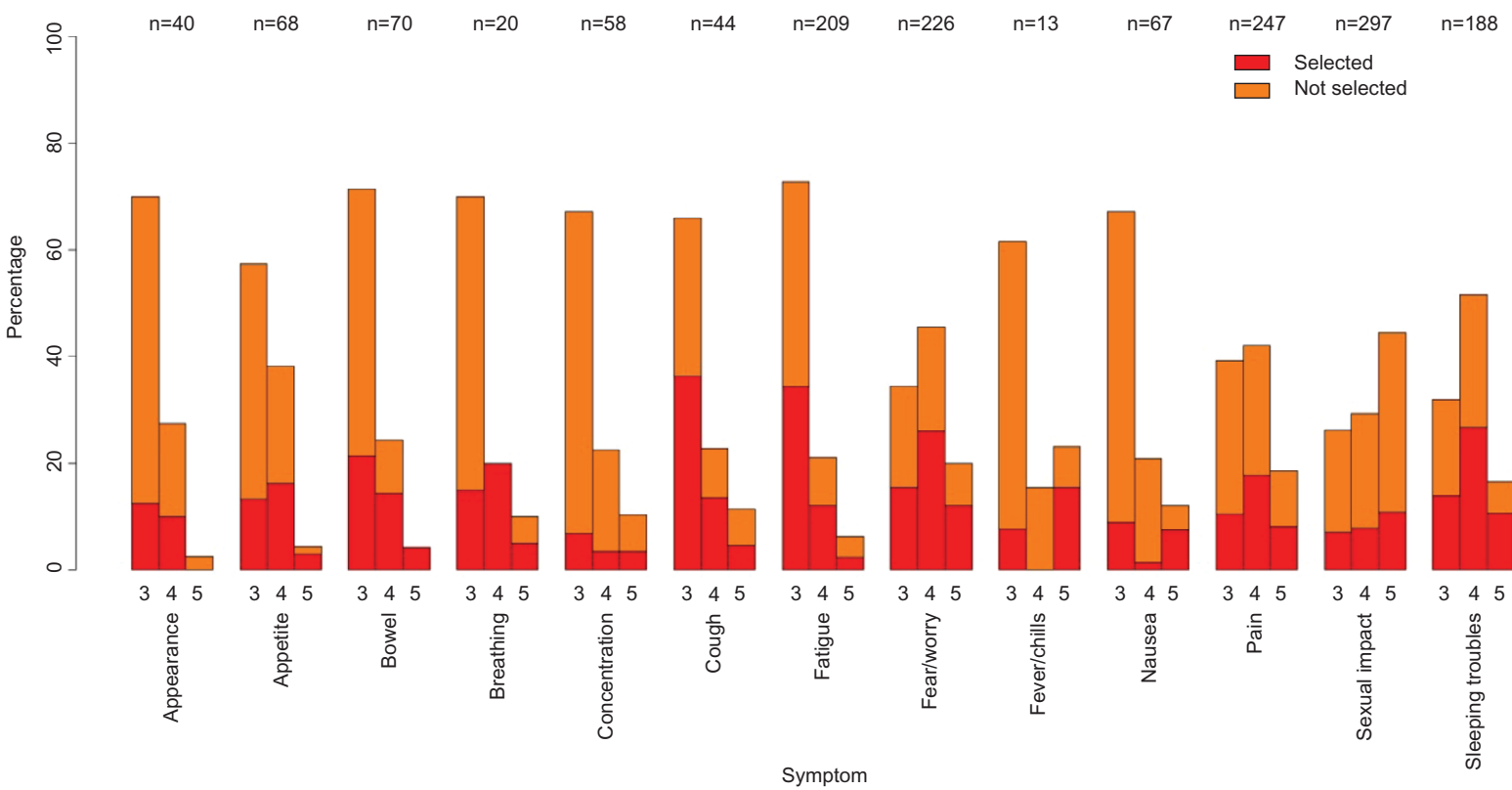

B

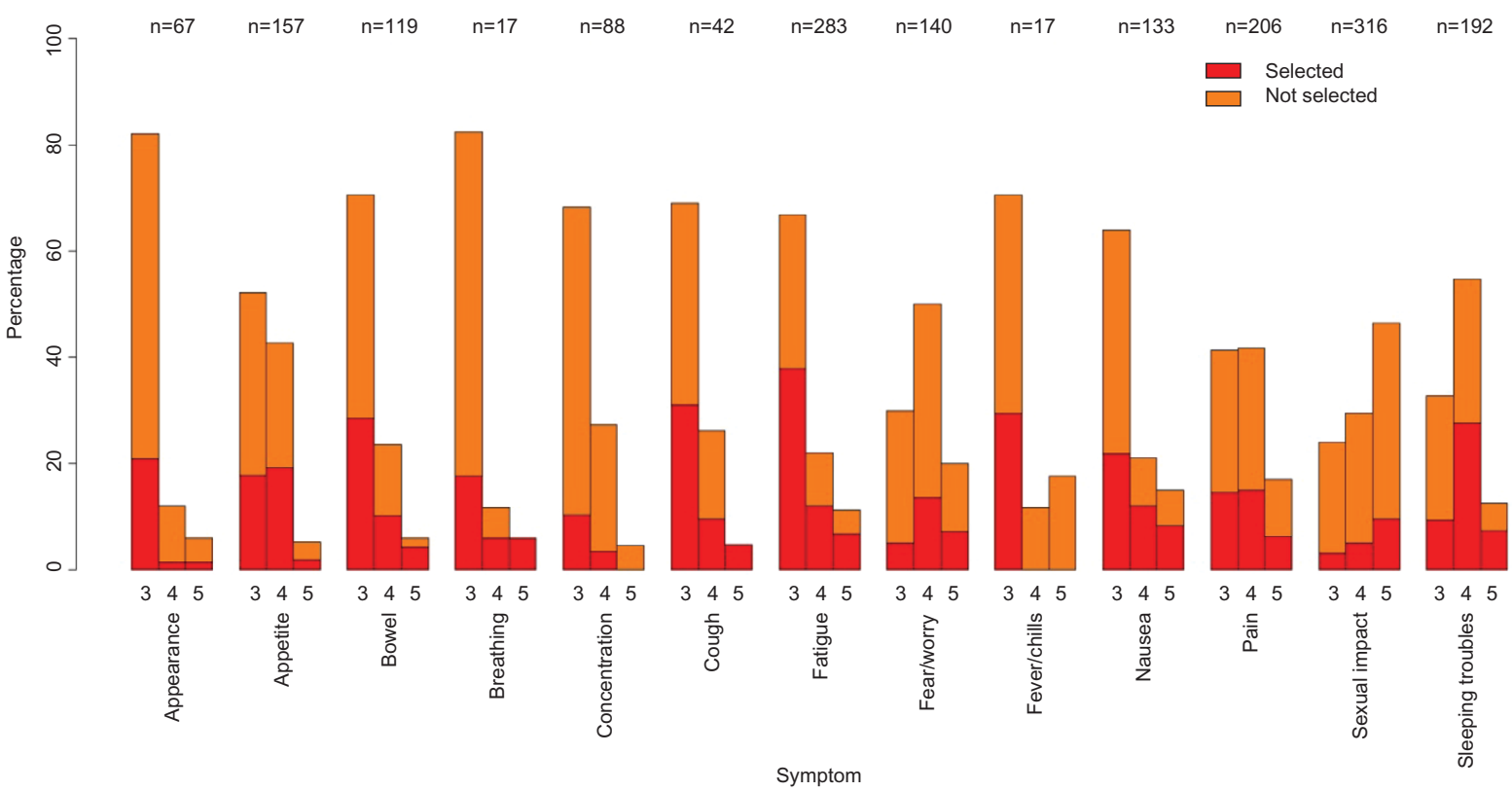

Figure 3 For each symptom, percentage of patients (the whole bar) reporting a score of 3, 4, or 5 and the percentage of patients selecting (red) and not selecting (orange) the given symptom of a given score as most bothersome issue, before treatment ( $\mathrm{TI}-\mathbf{A})$ and during treatment $(\mathrm{T} 2-\mathbf{B})$.

erate-to-severe distress, the absolute item score had predictive accuracy of $46 \%$ at $\mathrm{T} 1$ and $48 \%$ at T2, respectively (Table 3 ). In other words, the only symptom reported with moderateto-severe distress was also perceived as the most bothersome issue in $46 \%-48 \%$ participants. When two or more symptoms were reported as moderate-to-severe, the top two symptoms with highest SDS-15 item score correctly predicted the most bothersome issues for 79\% (T1) and 76\% (T2) participants.

When using symptoms with the largest positive difference to predict most bothersome issues at T2, it was corrected for $38 \%$ participants when only one symptom was moderate-to- severe and for $70 \%$ participants when two or more symptoms were moderate-to-severe (Table 3 ). In the sensitivity analysis, restricted to the same sample used in evaluating the change score, the prediction accuracy with the absolute score remained $76 \%$ when two or more symptoms were moderateto-severe (Table 3). The prediction accuracy improved 4\% when adding change scores on top of the absolute scores.

\section{Discussion}

This analysis of US patients with various cancer types and stages, treated at two comprehensive cancer centers, revealed 
Table 3 Prediction accuracy of SDS-15 absolute score and change score in identifying most bothersome issues.

\begin{tabular}{|c|c|c|c|c|}
\hline \multirow[t]{3}{*}{$\begin{array}{l}\text { Score used for } \\
\text { prediction }\end{array}$} & \multicolumn{4}{|c|}{$\begin{array}{l}\text { Number of moderate-to-severe symptoms } \\
\text { reported by patients }\end{array}$} \\
\hline & \multicolumn{2}{|l|}{ One } & \multicolumn{2}{|c|}{ Two or more } \\
\hline & $\begin{array}{l}\text { Number } \\
\text { of } \\
\text { patients }\end{array}$ & $\begin{array}{l}\text { Correct } \\
\text { predicted, } \\
\text { n (\%) }\end{array}$ & $\begin{array}{l}\text { Number } \\
\text { of } \\
\text { patients }\end{array}$ & $\begin{array}{l}\text { Correct } \\
\text { predicted, } \\
\text { n (\%) }\end{array}$ \\
\hline \multicolumn{5}{|l|}{ Absolute score } \\
\hline TI & 163 & 75 (46\%) & 370 & 292 (79\%) \\
\hline $\mathrm{T} 2$ & 117 & $56(48 \%)$ & 410 & $313(76 \%)$ \\
\hline Change score (T2) & 32 & $12(37 \%)$ & 311 & $219(70 \%)$ \\
\hline Absolute score $(\mathrm{T} 2)^{\mathrm{a}}$ & 32 & $12(37 \%)$ & 311 & $238(76 \%)$ \\
\hline
\end{tabular}

Notes: aSensitivity analysis - using the same sample as the one used in evaluating the change score. TI, before treatment; T2, during treatment.

Abbreviations: SDS-15, Symptom Distress Scale-15; TI, before treatment; T2, during treatment.

several important observations. First, significantly more participants experienced moderate-to-severe distress after start of treatment for the majority of symptoms. Impact on sexual activity/interest, fatigue, pain, and insomnia were the four symptoms reported with moderate-to-severe distress by more than $25 \%$ of participants both before and during treatment. However, the prevalence of fear/worry fell significantly after treatment initiation. Second, the likelihood that a symptom with moderate-to-severe distress was regarded as a most bothersome issue was different across symptoms. Moderate-to-severe cough, fatigue, fear/worry, and insomnia were the four symptoms more often regarded as most bothersome issues. Third, the absolute SDS-15 score identified participants' most bothersome issues with good accuracy and outperformed the change score.

Our findings are similar to prior work with regard to symptom prevalence. Kim et a ${ }^{10}$ reviewed 18 studies with sample sizes that ranged from 26 to 527 and reported that $40 \%-61 \%$ patients with cancer experienced more than one symptom. A recent study in older adults during cancer therapy reported a mean number of $5( \pm 3)$ symptoms per patient. ${ }^{3}$ The most prevalent cancer symptoms we identified before and during treatment, notably fatigue and pain, are consistent with other studies. ${ }^{10,18}$

Increased cancer symptomatology, after the first cycles of chemotherapy or first few weeks of radiation, is universally observed due to the common and frequent side effects of cancer therapies. Our results confirmed a higher prevalence of moderate-to-severe symptoms during active cancer treatment. Cleeland et $\mathrm{al}^{19}$ analyzed data from the Eastern Cooperative Oncology Group's multisite Symptom Outcomes and Practice Patterns study and reported that 33\% of 2,299 patients with various solid tumors receiving current cancer therapy reported at least three symptoms with moderate-to-severe distress. This rate was significantly higher than the $27 \%$ of 807 patients not on active therapy. The patient-reported measure used in the Symptom Outcomes and Practice Patterns study, the 19 -item M. D. Anderson Symptom Inventory, ${ }^{9}$ was similar in core symptoms to our measure, but different in response options $(0-10)$ and the patients were not assessed both before and after new therapy.

We confirmed, in a pretreatment setting and US patient population, the finding from Snyder et $\mathrm{al}^{17}$ that European patient self-reported symptom scores can identify most bothersome issues with good accuracy and that absolute scores work better than change score. However, the prediction accuracy was lower in our study. Two reasons potentially contributed to the discrepancy. First, participants who reported no bothersome issue were excluded in Snyder's study, but were included in our study. We considered a symptom deemed moderate-to-severe an inaccurate prediction when no bothersome issue was identified. Second, our study used a threshold of only moderate-to-severe (response $\geq 3$ of 5 ) symptoms from which participants selected most bothersome issues; Snyder's procedures included a list of all symptoms from which participants selected bothersome issues. Symptoms below the threshold score might have been most bothersome to our participants, but those issues were not offered in the list from which the participants chose the bothersome issues as we were most interested in which distressing symptoms could predict bother.

As in the work of Snyder et al, ${ }^{17}$ we found that fatigue and pain were not only reported most frequently, but also perceived frequently as most bothersome issues. Understanding how much a particular symptom bothers a patient is related to the self-appraisal of the particular symptom. A symptom with moderate level distress (eg, I frequently have trouble getting to sleep) may cause the patient a great deal of bother or impact on daily life at a given time point. Conversely, a symptom with high level of distress (eg, My cancer or treatment has had a lot of impact on my sexual activities and interests) may not bother the patient much at the same time point. We found in this study that a report of a higher score is not necessarily associated with a higher chance of patient selection as a most bothersome issue. Impact on sexual activity/interest was shown in our study as the most frequently experienced symptom $(>50 \%)$ with moderate-tosevere distress, but it was perceived as most bothersome issue by only approximately $10 \%$ of patients. Symptom priorities during active treatment may characteristically focus on what interferes with day-to-day living. Confirming the classic 
Maslow's hierachy, ${ }^{20}$ being very tired, not sleeping, and eating are logical first considerations by patients during treatment in an acute ambulatory care setting. Concerns related to sexual activity/interest likely come closer to the top of priorities once the acute period is completed.

The concept of symptom bother has been explored often in prostate cancer patient-reported outcome studies since the development of the Expanded Prostate Cancer Index Composite. ${ }^{21}$ When comparing survivor outcomes after various treatment management strategies in men with prostate cancer, Wei et $\mathrm{al}^{22}$ found that compared to two radiation treatment modalities, men who were at least 1 year postprostatectomy reported significantly more sexual and bladder dysfunction; yet only the sexual functioning was significantly bothersome. These results contrast with our findings about sexual activity/ interest, yet underscore the influence of sample (men only), trajectory (longer-term survival), and treatment type (surgical vs radiation).

The significant drop in moderate-to-severe fear/worry from pretreatment to on-treatment is a relevant finding, perhaps reflecting peace of mind achieved once the treatment had become familiar to the patient. Since the seminal paper of Zabora et al, ${ }^{23}$ psychological distress has been evaluated in various types of cancer pretreatment only ${ }^{24}$ and posttreatment survivorship. ${ }^{25}$ Pretreatment worry has been shown to be significantly higher in women about to receive chemotherapy than radiation therapy and correlated to neurocognitive dysfunction. ${ }^{26}$ However, little is known, if anything, about the impact of actually starting treatment on elevated pretreatment distress levels.

The generalizability of our findings to other samples may be limited; our sample was relatively homogenous in terms of race and education and was limited to patients treated at comprehensive cancer centers. Only 13 symptoms were studied, therefore, information on frequencies and severity of other disease or treatment-related symptoms were not available. We included participants who had only one or two symptoms rated moderate-to-severe into the predictive analyses, without knowing how they interpret selecting two most bothersome issues when only one or two symptoms were listed for selection. Furthermore, we only measured symptoms immediately before a new cancer therapy and during the acute phase of treatment. Our findings cannot be generalized beyond this timeframe, for example, into posttherapy survivorship.

\section{Conclusion and clinical implication}

Symptom scores collected just prior to a clinic visit, though demonstrated to be predictive of bother, may not be perfectly accurate without understanding bother. A combination of the symptom report score plus the patient's prioritization of problematic or bothersome symptoms may be most helpful to a clinician about to conduct a verbal history with subsequent symptom analysis. The most bothersome symptom gives the clinician a place to start when synthesizing all information about a patient during cancer therapy.

\section{Acknowledgment}

The work was supported by Grant No R01 NR008726 from the National Institute of Nursing Research, National Institutes of Health.

\section{Disclosure}

The authors report no conflicts of interest in this work.

\section{References}

1. McCorkle R, Young K. Development of a symptom distress scale. Cancer Nurs. 1978;1(5):373-378

2. Akin S, Can G, Aydiner A, Ozdilli K, Durna Z. Quality of life, symptom experience and distress of lung cancer patients undergoing chemotherapy. Eur J Oncol Nurs. 2010;14(5):400-409.

3. Cheng KK, Yeung RM. Symptom distress in older adults during cancer therapy: impact on performance status and quality of life. $J$ Geriatr Oncol. 2013;4(1):71-77.

4. Van Cleave JH, Egleston BL, Ercolano E, McCorkle R. Symptom distress in older adults following cancer surgery. Cancer Nurs. 2013;36(4):292-300.

5. Wu HS, Harden JK. Symptom burden and quality of life in survivorship: a review of the literature. Cancer Nurs. 2015;38(1):E29-E54.

6. Basch E, Artz D, Dulko D, et al. Patient online self-reporting of toxicity symptoms during chemotherapy. J Clin Oncol. 2005;23(15):3552-3561.

7. Berry DL, Hong F, Halpenny B, et al. Electronic self-report assessment for cancer and self-care support: results of a multicenter randomized trial. J Clin Oncol. 2014;32(3):199-205.

8. Cleeland CS. Symptom burden: multiple symptoms and their impact as patient-reported outcomes. J Natl Cancer Inst Monogr. 2007;37:16-21.

9. Cleeland CS, Mendoza TR, Wang XS, et al. Assessing symptom distress in cancer patients: the M.D. Anderson Symptom Inventory. Cancer. 2000;89(7):1634-1646.

10. Esther Kim JE, Dodd MJ, Aouizerat BE, Jahan T, Miaskowski C. A review of the prevalence and impact of multiple symptoms in oncology patients. J Pain Symptom Manage. 2009;37(4):715-736.

11. Brassell SA, Elsamanoudi SI, Cullen J, Williams ME, McLeod DG. Healthrelated quality of life for men with prostate cancer - an evaluation of outcomes 12-24 months after treatment. Urol Oncol. 2013;31(8):1504-1510.

12. Hoekstra J, Vernooij-Dassen MJ, de Vos R, Bindels PJ. The added value of assessing the 'most troublesome' symptom among patients with cancer in the palliative phase. Patient Educ Couns. 2007;65(2):223-229.

13. Siefert ML, Hong F, Valcarce B, Berry DL. Patient and clinician communication of self-reported insomnia during ambulatory cancer care clinic visits. Cancer Nurs. 2014;37(2):E51-59.

14. Berry DL, Wilkie DJ, Thomas CR Jr, Fortner P. Clinicians communicating with patients experiencing cancer pain. Cancer Invest. 2003;21(3):374-381.

15. Kennedy Sheldon L, Hilaire D, Berry DL. Provider verbal responses to patient distress cues during ambulatory oncology visits. Oncology Nurs Forum. 2011;38(3):369-375.

16. Salsman JM, Grunberg SM, Beaumont JL, et al. Communicating about chemotherapy-induced nausea and vomiting: a comparison of patient and provider perspectives. J Natl Compr Canc Netw. 2012;10(2):149-157. 
17. Snyder CF, Blackford AL, Aaronson NK, et al. Can patient-reported outcome measures identify cancer patients' most bothersome issues? J Clin Oncol. 2011;29(9):1216-1220.

18. Teunissen SC, Wesker W, Kruitwagen C, de Haes HC, Voest EE, de Graeff A. Symptom prevalence in patients with incurable cancer: a systematic review. J Pain Symptom Manage. 2007;34(1):94-104.

19. Cleeland CS, Zhao F, Chang VT, et al. The symptom burden of cancer: Evidence for a core set of cancer-related and treatment-related symptoms from the Eastern Cooperative Oncology Group Symptom Outcomes and Practice Patterns study. Cancer. 2013.

20. Maslow A. A theory of human motivation. Psych Rev. 1943;50:370-398.

21. Wei JT, Dunn RL, Litwin MS, Sandler HM, Sanda MG. Development and validation of the expanded prostate cancer index composite (EPIC) for comprehensive assessment of health-related quality of life in men with prostate cancer. Urology. 2000;56(6):899-905.
22. Wei JT, Dunn RL, Sandler HM, et al. Comprehensive comparison of health-related quality of life after contemporary therapies for localized prostate cancer. J Clin Oncol. 2002;20(2):557-566.

23. Zabora J, BrintzenhofeSzoc K, Curbow B, Hooker C, Piantadosi S. The prevalence of psychological distress by cancer site. Psychooncology. 2001;10(1):19-28.

24. Steinberg T, Roseman M, Kasymjanova G, et al. Prevalence of emotional distress in newly diagnosed lung cancer patients. Supportive Care Cancer. 2009;17(12):1493-1497.

25. Butow PN, Bell ML, Smith AB, et al. Conquer fear: protocol of a randomised controlled trial of a psychological intervention to reduce fear of cancer recurrence. BMC Cancer. 2013;13(1):201.

26. Berman MG, Askren MK, Sook Jung M, et al. Pretreatment worry and neurocognitive responses in women with breast cancer. Health Psychol. 2014;33(3):222-231.
Patient Related Outcome Measures

\section{Publish your work in this journal}

Patient Related Outcome Measures is an international, peer-reviewed, open access journal focusing on treatment outcomes specifically relevant to patients. All aspects of patient care are addressed within the journal and practitioners from all disciplines are invited to submit their work as well as healthcare researchers and patient support groups.

\section{Dovepress}

The journal is included in PubMed. The manuscript management system is completely online and includes a very quick and fair peer-review system. Visit http://www.dovepress.com/testimonials.php to read real quotes from published authors.

Submit your manuscript here: http://www.dovepress.com/patient-related-outcome-measures-journal 